\title{
Diagnóstico diferencial de trombose aortoilíaca e mieloencefalite protozoária equina: relato de caso
}

[Differential diagnosis between aorto-iliac thrombosis and equine protozoal myeloencephalitis: case report]

\author{
P.B. Escodro ${ }^{1}$, P.F.R. Lopes $^{2}$, C.G. Gianini ${ }^{2}$, D.N. Jorge Filho ${ }^{2}$ \\ ${ }^{1}$ Universidade Federal de Alagoas - Campus Arapiraca - Polo Viçosa \\ Rodovia José Aprígio Brandão Vilela,s/n \\ 57700-000 - Viçosa, AL \\ ${ }^{2}$ Médico veterinário autônomo
}

\begin{abstract}
RESUMO
Relata-se o caso de uma égua de atividade de polo, que apresentou inicialmente claudicação leve no membro posterior esquerdo, a qual evoluiu para ataxia e atrofia da musculatura glútea do lado esquerdo, com diagnóstico de trombose aortoilíaca (TAI). A paciente foi tratada com suspeita de mieloencefalite protozoária equina, devido à semelhança dos sinais clínicos com essa doença, porém o líquido cefalorraquidiano apresentou-se negativo para anticorpos anti-Sarcocystis neurona. A palpação transretal indicou uma massa na bifurcação aortoilíaca esquerda. Na avaliação ultrassonográfica, visualizou-se imagem hiperecoica aderida ao endotélio vascular, sugerindo TAI atingindo a estenose de $70 \%$ da luz arterial.
\end{abstract}

Palavras-chave: equino, trombose aortoilíaca, mieloenceafalite protozoária equina, diagnóstico diferencial

\begin{abstract}
The case of a mare used for polo is reported. The animal showed clinical signs of soft lameness of the hindlimb, evolving to ataxia and gluteal muscle atrophy, with aorto-iliac thrombosis (AIT). The patient was treated with the suspect of equine protozoal myeloencephalitis (EPM), due to the resemblance of clinical signs. Cerebrospinal fluid analysis was negative for antibodies against Sarcocystis neurona. The transrectal examination indicated a mass in the left aorto-iliac bifurcation. In the ultrasonographic evaluation, a hyperechoic image adhered to the vascular endothelium was observed, suggesting (AIT), occupying $70 \%$ of arterial lumen. The present article has the objective of pointing out the importance of the differential diagnosis between AIT and EPM in horses with ataxia in hindlimbs and muscular atrophy.
\end{abstract}

Keywords: equine, aorto-iliac thrombosis, equine protozoal myeloencephalitis, differential diagnosis

\section{INTRODUÇÃO}

A trombose aorto-ilíaca (TAI) é definida como o processo obstrutivo, total ou parcial, que ocorre na aorta abdominal e em seu ramo da artéria ilíaca. Trata-se de uma doença incomum, mas potencialmente séria em equídeos e que gera polêmica em relação à sua etiopatogenia. Pode acometer equinos, bovinos, caninos e felinos (Reed e Bayly, 2000; Oyamada et al., 2007). TAI idiopática foi descrita, em humanos, por Kohli e Lodha (2006), em um recém-nascido

Recebido em 13 de outubro de 2009

Aceito em 10 de setembro de 2010

E-mail: pierre.vet@gmail.com aparentemente saudável, sem fatores de risco associados, por meio da cateterização da artéria umbilical.

A etiologia da TAI em equinos está associada às infecções bacterianas, às injúrias mecânicas das artérias e ao estresse, mas o parasitismo por Delafondia (Strongylus) vulgaris compreende a maioria dos casos, fornecendo a lesão primária de aterite obstrutiva, responsável pelos demais sinais (Oyamada et al., 2007). Os animais mais acometidos são os cavalos de corrida (Zambrano 
e Moreira, 2002). Maxie e Physick-Sheard (1985) concluíram que a incidência é maior em equinos machos, pesados e de idade avançada.

Observam-se duas formas de manifestação clínica nos equinos: a leve, em que a obstrução não chega a afetar significativamente o fluxo sanguíneo, causando claudicação, unilateral ou bilateral, e a aguda, quando o cavalo manifesta sinais de ansiedade, taquicardia, taquipneia, relutância em caminhar, suor profuso, exceto no membro afetado, e que evoluindo para óbito. A atrofia muscular da região glútea pode estar presente em ambas as formas. Em humanos, o sintoma mais comum de doença arterial oclusiva das extremidades é a claudicação intermitente (Dewolfe et al., 1954; Zambrano e Moreira, 2002; Oyamada et al., 2007).

O diagnóstico é estabelecido com base no histórico, em sinais clínicos - mediante exame retal - e é confirmado com a ultrassonografia transretal (Reef et al., 1987; Ross et al., 1997). O tratamento geralmente não produz resultados satisfatórios, com prognóstico reservado a desfavorável. Trachsel et al. (2008) obtiveram bons resultados no tratamento, com heparina continuado com femprocumona por sete meses, de uma égua que apresentava claudicação intermitente.

A mieloencefalite protozoária equina (MPE) é uma enfermidade que acomete o sistema nervoso central do equino e é causada pelo parasita Sarcocystis neurona. Acomete mais as raças Puro Sangue Inglês, Quarto de Milha e Standardbred Americano (Rushing, 2006).

Na MPE, os sinais são variáveis, porém a ataxia é o sinal clínico mais evidente, por apresentar a sensação de o animal "ter esquecido" o membro ao se levantar, por isso também é conhecida como "bambeira". O animal pode apresentar atrofia assimétrica dos músculos quadríceps e glúteos em qualquer estágio da doença (Furr et al., 2002).

O diagnóstico é realizado por meio de exames imunodiagnósticos do soro ou do líquido cefalorraquidiano (LCR) para a detecção de anticorpos contra $S$. neurona. O tratamento é à base de sulfonamidas, pirimetamina, diclazuril ou toltrazuril, por via oral, podendo durar entre 21 e 90 dias (Stelmann e Amorim, 2010).
O objetivo deste trabalho foi descrever o caso de um equino com ataxia de membros posteriores e atrofia glútea, com suspeita clínica de MPE e confirmação de diagnóstico de TAI, mostrando a importância do diagnóstico diferencial entre as duas enfermidades.

\section{CASUÍSTICA}

Uma égua, Puro Sangue Inglês, de alto desempenho no polo nacional, com 12 anos de idade, $430 \mathrm{~kg}$, foi recebida no Hospital Veterinário de Equinos Vetpolo (HVP), na cidade de Indaiatuba-SP, com a indicação de ataxia de membros posteriores e atrofia de musculatura glútea.

$\mathrm{Na}$ anamnese, foi relatado que a sintomatologia clínica iniciou-se há aproximadamente sete meses, quando o quadro inicial era de claudicação grau 1 no membro posterior esquerdo, com aumento para grau 2 após a atividade física. Nesse mesmo período, a paciente apresentava leve atrofia muscular da região glútea no mesmo lado. $\mathrm{Na}$ ocasião, o diagnóstico clínico prévio foi de MPE, sendo prescrito o tratamento com Diclazuril (10mg/kg/VO/sid) durante 60 dias.

Segundo histórico clínico fornecido, após uma semana do diagnóstico prévio, o animal foi submetido à coleta do LCR, sob anestesia geral. $\mathrm{O}$ procedimento anestésico foi realizado mediante administração de acepromazina (Acepran - Univet S/A - São Paulo, Brasil) na dose de 0,05mg/kg/IV, e, após 10 minutos, de cloridrato de xilazina (Sedazine - Fort Dodge Animal Health - Iowa, EUA), na dose de 0,5mg/kg/IV, ambos utilizados como medicação pré-anestésica (MPA). Para a indução anestésica, foi utilizado Diazepan (Compaz - Cristália Prod. Quím. Fam. Ltda. - Itapira, Brasil), na dose de $0,1 \mathrm{mg} / \mathrm{kg}$, e cloridrato de ketamina (Dopalen Ceva Saúde Animal Ltda. -Paulínia, Brasil), na dose de $2 \mathrm{mg} / \mathrm{kg} / \mathrm{IV}$. A manutenção anestésica foi com éter gliceril guaiacol (Henri Farma Prod. Quím. Farm. Ltda.- São Paulo, Brasil), na dose de $50 \mathrm{mg} / \mathrm{kg}$, diluído em $500 \mathrm{~mL}$ de solução fisiológica, na velocidade de 160 macrogotas por minuto. Com a paciente em decúbito lateral direito, a região da nuca foi amplamente tricotomizada, e a antissepsia realizada com clorexidine a $0,5 \%$, em solução alcoólica. Com o pescoço flexionado, procedeu-se à colheita do 
LCR, na articulação atlanto-occipital, utilizandose cateter 16G (Becton Dickinson-Curitiba, Brasil).

O material colhido e resfriado foi enviado para a Kentucky University (Lexington, $K Y$ ) para detecção de anticorpos anti-Sarcocystis neurona, por meio do teste de Immunoblot (Western Blot), que não apresenta reação cruzada com outros tipos de protozoários e tem especificidade e sensibilidade de aproximadamente 89\% ( Dubey et al., 2001).

O resultado do teste, após 40 dias, não confirmou a suspeita clínica de MPE. Mesmo assim, o proprietário seguiu a prescrição inicial, continuando por mais 20 dias, com a administração oral de Diclazuril (Hiprosil Vansil Ind.Veterinária Ltda. - Descalvado, Brasil). A égua foi retirada do esporte por aproximadamente 150 dias. Mesmo com o repouso da atividade esportiva, a paciente apresentou aumento da atrofia muscular e persistência dos sinais clínicos iniciais, o que levou o seu encaminhamento ao HVP.

Ao exame clínico, a égua apresentava claudicação grau 1 no membro posterior esquerdo e leve ataxia. No exame neurológico do apoio de cauda, o animal sugeria "esquecer" o membro. Ao estímulo doloroso na coroa do casco, a paciente reagia com menor intensidade e com relativo atraso no membro posterior esquerdo, em relação ao membro posterior direito.

A atrofia da musculatura glútea do lado esquerdo era acentuada (Fig. 1), e não foi evidenciada atrofia ou fraqueza em outras regiões musculares, ficando os sinais clínicos restritos ao membro acometido. Além disso, a paciente não apresentava distúrbios na ingestão e deglutição de alimentos, e o escore corporal era muito bom, sem que ocorresse emagrecimento ou dificuldade em se alimentar.

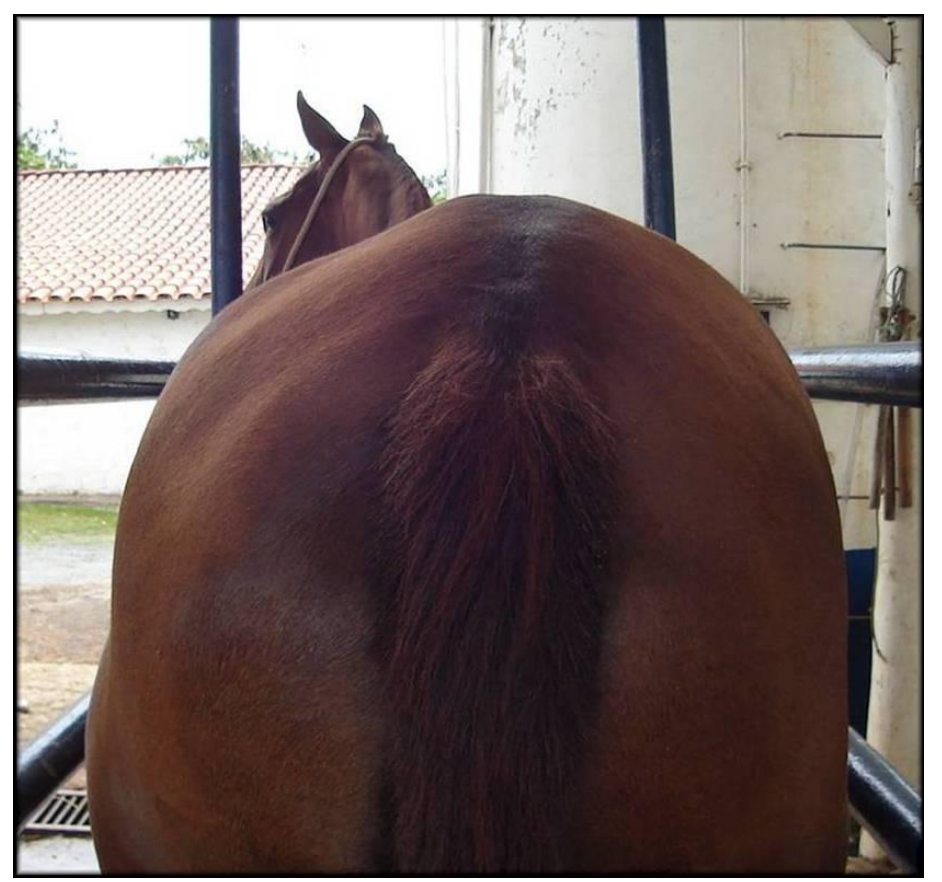

Figura 1. Égua Puro Sangue Inglês, 12 anos, apresentando atrofia muscular assimétrica acentuada na região glútea.

Durante a palpação transretal, notaram-se aumento de volume e consistência na bifurcação aortoilíaca esquerda. Ao exame diagnóstico complementar com aparelho de ultrassonografia (Aloka SSD 500 - Aloka Co. - Tokio, Japão) utilizando transdutor linear de $7,5 \mathrm{MHz}$, constatou-se trombose aortoilíaca, com área estenosada de aproximadamente $70 \%$, sugerindo aneurisma. 
O diagnóstico foi de trombose aortoilíaca esquerda, com etiologia indeterminada, já que os animais da propriedade são submetidos a exames coproparasitológicos semestrais e protocolos de desverminação trimestrais com ivermectina e praziquantel (Equimax - Virbac do Brasil Ind. Com. Ltda. - São Paulo, Brasil), alternados com moxidectina (Equest - Fort Dodge Saúde Animal Ltda. - Campinas, Brasil) e febendazole com triclorfon (Panacur Composto Intervet/Schering-Plough - Cotia, Brasil).

\section{DISCUSSÃO E CONCLUSÃO}

O presente artigo objetiva salientar a importância do diagnóstico diferencial entre a TAI e a MPE em cavalos com ataxia nos membros posteriores e atrofia muscular.

A MPE pode ser confundida com outras doenças que causam distúrbios neurológicos. Os principais diagnósticos de confundimento são de mielopatia estenótica cervical, mieloencefalopatia degenerativa equina, mieloencefalopatia com neurite/vasculite causada pelo Herpesvírus equino do tipo $1 \mathrm{e}$ trauma. Em casos suspeitos com apresentação de déficits de pares de nervos cranianos, deve-se realizar o diagnóstico diferencial de síndrome da cauda equina, doença das bolsas guturais, otite média/interna e outras neuropatias periféricas, como o traumatismo craniano com comprometimento somente de nervos periféricos. Nos equinos que apresentam sinais cerebrais, déficits dos nervos cranianos e/ou ataxia, consideram-se como causa as encefalites virais e bacterianas, a leucoencefalomalácea, o traumatismo craniano e a encefalopatia hepática/urêmica. Entre outras afecções que podem apresentar sintomatologia semelhante à MPE, pode-se destacar: doença do neurônio motor, neoplasias da coluna vertebral e/ou da medula espinhal, abscessos epidurais, encefalite viral do Oeste do Nilo, malformações vasculares, traumas, abscessos cerebrais, migração parasitária, epilepsia, linfossarcomas e botulismo (MacKay et al., 2000; Dubey et al., 2001; Stelmann e Amorim, 2010). Assim, a TAI não é citada como possível diagnóstico diferencial de MPE.

A TAI compreende vários fatores de risco que, além da migração de Delafondia vulgaris, podem incluir ambiente, nutrição, idade, sexo, hereditariedade, coagulação sanguínea, endoarterite e hemodinâmica (Reed e Bayly, 2000; Oyamada et al., 2007).

Confrontando-se as informações entre a MPE e a TAI, nota-se que a migração de parasitas pode ser considerada no diagnóstico diferencial de MPE. Segundo Oyamada et al. (2007), a migração por Delafondia vulgaris é a principal causa de TAI. Dessa forma, a patogenia inerente à migração parasitária, que evolui para TAI em equinos, indiretamente já se compõe como diagnóstico diferencial entre TAI e MPE, que é o objetivo deste trabalho.

Outro ponto a ser relevado é a incidência de TAI por etiopatogenia hemodinâmica e não parasitária em cavalos de esporte, já que a maioria dos animais de alto rendimento tem programas de desverminação, como o encontrado neste relato de caso.

No cotidiano clínico de animais de esporte, principalmente naqueles que os esbarros e as viradas bruscas são constantes, notam-se muitas claudicações inespecíficas nos membros posteriores, podendo ser acompanhadas de atrofias musculares, muitas vezes sugerindo quadros neurológicos. $\mathrm{O}$ traumatismo na bifurcação aortoilíaca pode estar associado à injúria mecânica das artérias devido à hiperextensão ou rotações abruptas do membro posterior, provocando microlesões endoteliais, com posterior formação cicatricial de trombos.

Com o apoio deste caso, levanta-se hipótese de TAI ser proveniente de acidentes hemodinâmicos, com a possibilidade de não estar associada ao parasitismo por $D$. vulgaris ou a infecções bacterianas, mas sim por injúrias mecânicas agudas ou repetitivas, relacionadas ao esporte, na bifurcação aortoilíaca. Porém, independente da eficácia antiparasitária dos vermífugos utilizados, a longevidade do processo de migração larval subendotelial e suas consequências inflamatórias causarão lesões graves a longo prazo e de difícil recuperação. Dessa forma, o estabelecimento da relação direta entre o programa terapêutico antiparasitário e as ocorrências de TAI é difícil, sendo necessário relatar maior número de casos, correlacionandoos com a ocorrência ou não de parasitoses e, no caso de animais de alto desempenho, ao tipo de esporte realizado. 
Assim, a realização da palpação transretal em animais com claudicação posterior leve intermitente e/ou com ataxia, principalmente naqueles quadros iniciais sugestivos de MPE, pode ser uma opção nos casos duvidosos. Neste exame, a diferença entre as bifurcações aortoilíacas é facilmente detectada, com confirmação diagnóstica da trombose por meio da ultrassonografia, compondo o diagnóstico diferencial entre MPE e TAI.

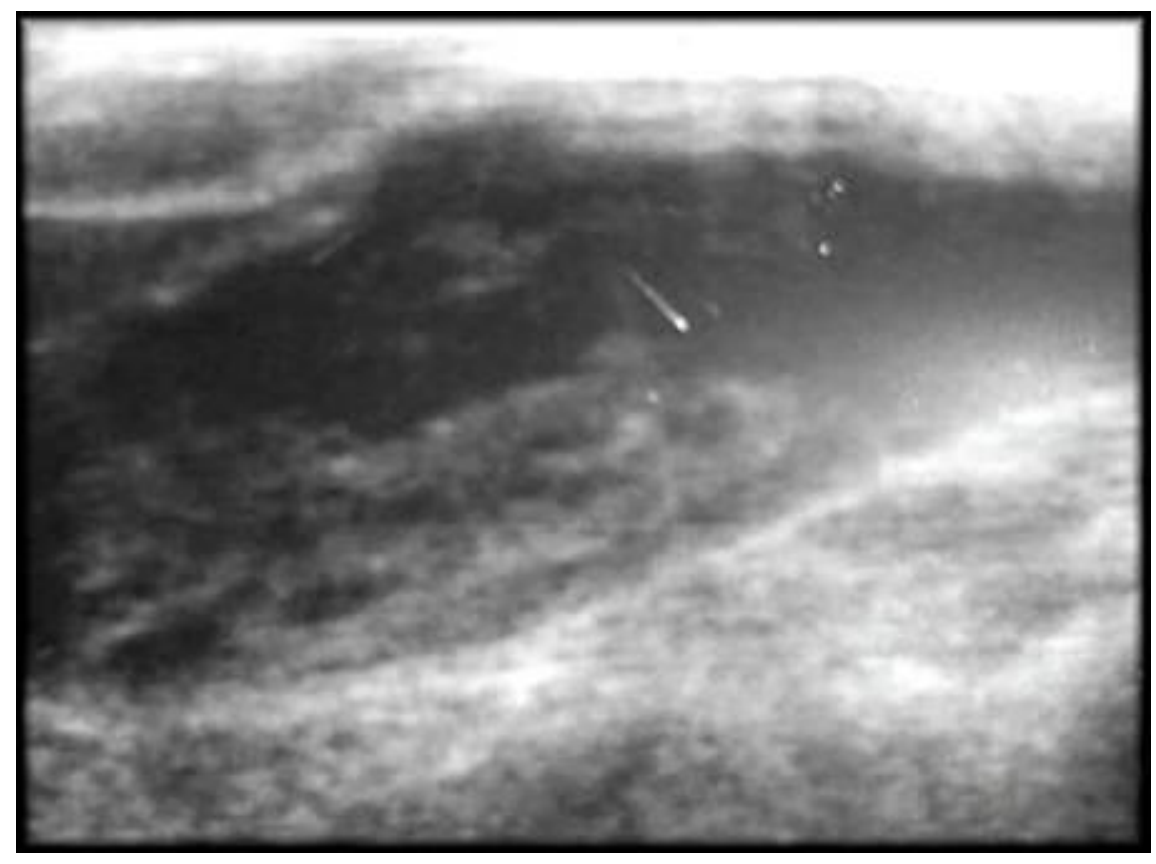

Figura 2. Imagem ultrassonográfica indicando presença de trombose arterial próximo à junção aorto-ilíaca esquerda.

Conclui-se que a TAI deve ser considerada no diagnóstico diferencial de MPE e pode ser mais frequente em equinos do que é relatada, sugerindo investigação clínica profunda da região aortoilíaca em pacientes portadores de claudicação crônica, ataxia e atrofia muscular, com diagnóstico indeterminado, bem como o levantamento das etiopatogenias da TAI, correlacionando-as com a migração de $D$. vulgaris.

\section{REFERÊNCIAS BIBLIOGRÁFICAS}

DEWOLFE, V.G.; HUMPHRIES, A.W.; LEFEVRE, F.A. et al. Intermittent claudication of the hip and the syndrome of chronic aortoiliac thrombosis. J. Am. Heart Assoc., v.9, p.116, 1954.

DUBEY, J.P.; LINDSAY, D.S.; SAVILLE W.J.A. et al. A review of Sarcocystis neurona and equine protozoal myeloencephalitis (EPM). Vet. Parasitol., v.95, p.89-131,2001.
FURR, M.; MacKAY, R.; GRANSTROM, D. et al. Clinical diagnosis of equine protozoal myeloencephalitis (EPM). J. Vet. Intern. Med., v.16, p.618-621, 2002.

KOHLI, U.; LODHA, R. Idiopathic neonatal aortic thrombosis. Indian J. Pediatr., v.73, p.1127-1129, 2006.

MACKAY, R.J.; GRANSTROM, D.E.; SAVILLE, W.J.A. et al. Equine protozoal myeloencephalitis. Vet. Clin. N. Am.: Equine Pract., v.16, p.405-425, 2000.

MAXIE, M.G.; PHYSICK_SHEARD, P.W. Aortic-iliac thrombosis in horses. Vet. Pathol., v.22, p.238-249, 1985.

OYAMADA, T.; SAIGAMI, K.; PARK, C. et al. Pathology of aortic-iliac thrombosis in two horses. J. Equine Sci., v.18, p.59-65, 2007.

REED, S.M.; BAYLY, W.M. Trombose aortoilíaca. In: Medicina interna equina. Rio de Janeiro: Guanabara Koogan, 2000. p.337-38. 
REEF, V.B.; ROBY, K.A.; RICHARDSON, D.W. et al. Use of ultrasonography for the detection of aortic-iliac thrombosis in horses. $J$. Am. Vet. Med. Assoc., v.3, p.286-288, 1987.

ROSS, M.W.; MAXSON, A.D.; STACY, V.S. et al. First-pass radionuclide angiography in the diagnosis of aortoiliac thromboembolism in a horse. Vet. Radiol. Ultrasound, v.3, p.226-230, 1997.

RUSHING, V. Silent killer of horses, 2006. Department of bacteriology. University of Wisconsin-Madison. Disponível em <www.bact.wisc.edu/microtextbook/index> Acessado em: 5 fev. 2009.
STELMANN, U.J.P.; AMORIM, R.M. Mieloencefalite protozoária equina. Vet. Zootec., v.17, p.163-176, 2010.

TRACHSEL, D.; COHAUSZ, O.; SCHARF, G. et al. Aorto-iliac thrombosis in a gelding treated with the anticoagulant phenprocoumon (Marcoumar). Schweiz. Archiv. Fur Tierheilkd., v.150, p.613-618, 2008.

ZAMBRANO, R.S.; MOREIRA, M. Trombose da artéria ilíaca em Equino. In: CONGRESSO BRASILEIRO DE MEDICINA VETERINÁRIA, 29., 2002, Gramado. Anais... Gramado, 2002. 